\title{
Hypolipaemic nutraceutics: red yeast rice and Armolipid, berberine and bergamot
}

 \\ ${ }^{1}$ National Institute of Public Health - National Institute of Hygiene, Warsaw, Poland \\ ${ }^{2}$ Institute of Rural Health, Lublin, Poland \\ A - Research concept and design, B - Collection and/or assembly of data, C - Data analysis and interpretation, \\ $D$ - Writing the article, E-Critical revision of the article, F- Final approval of article
}

Kłosiewicz-Latoszek L, Cybulska B, Stoś K, Tyszko P Hypolipaemic nutraceutics: red yeast rice and Armolipid, berberine and bergamot. Ann Agric Environ Med. 2021; 28(1): 81-88. doi: 10.26444/aaem/130629

\begin{abstract}
Introduction. Increased serum cholesterol levels constitute one of the main risk factors for cardiovascular diseases. Statins are a major method for reducing the levels which also lower the risk of cardiovascular events. However, these valuable drugs cannot be used in all patients who need them due to contraindications and intolerance. In such cases, help can be sought from nutraceutics that reduce the serum cholesterol concentration. Since there are numerous products of this type available at drugstores, registered as supplements, there seems to be a need to demonstrate their effectiveness in preventing cardiovascular diseases induced by atherosclerosis. In literature, increasingly more attention is drawn to red yeast rice, Armolipid, berberine and bergamot.

Brief description. This article presents knowledge about these nutraceutics based on clinical studies and expert statements relating to their use. The results of clinical studies and metaanalyses have shown that nutraceutics with cholesterol lowering properties, red yeast rice and Armolipid are the most favourable for reducing cardiovascular events. However, the evidence of benefits of berberine and bergamot is not so conclusive.

Conclusions. Red yeast rice products and Armolipid may be used as an alternative treatment in statin intolerant patients, especially in combination with ezetimibe. These nutraceutics can be also considered, as an adjunct to diet therapy in primary prevention of cardiovascular diseases in patients with mild and moderate hypercholesterolaemia. The opinion of experts on berberine and bergamot is ambiguous.
\end{abstract}

Key words

hypolipaemic nutraceutics, red yeast rice, berberine, bergamot, indications

\section{INTRODUCTION}

Hypolipaemic nutraceutics are very diverse in terms of their mechanism of action and effectiveness in reducing the cholesterol level. However, the hypolipaemic effects of nutraceutics cannot be compared with modern combined pharmacotherapy which achieve very low LDL cholesterol (LDL-C) concentrations, currently recommended in secondary prevention associated with a very high reduction of cardiovascular episodes [1]. However, some of them can be used in specific cases.

\section{OBJECTIVE}

The aim of the study is to familiarise the reader with the mechanism of action, clinical studies and therapeutic indications of selected nutraceutics based on current literature data. The analysis covers red rice and Armolipid, as well as berberine and bergamot, which are often recommended for cholesterol level reduction. This article presents current knowledge and expert statements.

Address for correspondence: Longina Kłosiewicz-Latoszek, National Institute of Public Health - National Institute of Hygiene, Warsaw, Poland

E-mail: Iklosiewicz@pzh.gov.pl

Received: 01.09.2020; accepted: 18.11.2020; first published: 02.12.2020

\section{MATERIALS AND METHOD}

Red yeast rice. Red yeast rice (RYR) has been used for many centuries in Asian countries as a colouring agent and a versatile medicine, and has aroused interest among western researchers, especially in the $21^{\text {st }}$ century, thanks to its cholesterol lowering properties which may have practical implications for statin-intolerant patients $[2,3,4,5]$. Red yeast rice is obtained through the fermentation of regular rice with the mould species Monascus purpureus. During fermentation, a red colour and a range of active substances showing pharmacological and toxic action are produced. The former include monacolins, especially monacolin $\mathrm{K}$, while the latter - citrinin. Monacolin K is structurally identical to lovastatin, which is the primary reason why RYR shows its hypolipaemic effects [3]. Monacolin $\mathrm{K}$ is available in two forms, i.e. lactone (inactive form) and hydroxylic acid (active form) $[2,4]$, which is absorbed better. Therefore, the latter form participates in the reduction of total cholesterol and LDL-C. Monacolin K, in the same way as lovastatin and other statins, inhibits 3-hydroxy-3-methyl-glutaryl-coenzyme A reductase (HMG CoA), the main enzyme responsible for cholesterol synthesis in the liver [2]. This results in an elevated activity of the LDL receptors on hepatocytes.

Monacolin $\mathrm{K}$ is catabolised in the liver, by 3A4 enzymes of cytochrome 450 (CYP 450), which participate in the catabolism of many drugs, and glycoprotein $\mathrm{P}[2,6]$. Hence, the possibility of muscular symptoms when taking RYR and other drugs that inhibit CYP3A4. Some RYR formulations 
contain toxic substances, such as citrinin, which causes kidney damage (glomerular endothelial hyperplasia, increased risk of adenomas and other tumours). Citrinin is harmful to the growth of an embryo in vitro and in vivo, and is therefore both nephrotoxic and teratogenic [4].

RYR formulations are available in capsules in a powdered form. The problem is that not all products are standardised and there is often a lack of information on the monacolin $\mathrm{K}$ content. RYR formulations vary significantly in terms of the quantity of this active substance [7], which can differ from that declared by the manufacturer [8]. Another issue is that citrinin may also be present, although it should not be in any amount. However, there are RYR products with a citrinin content that considerably exceeds its acceptable intake.

In people with mild to moderate hypercholesterolaemia who are healthy and those at a high risk of cardiovascular diseases, RYR formulations reduce total cholesterol (TC) levels by $16-31 \%$, LDL-C by $22-32 \%$ and triglycerides (TG) by $0-36 \%$ at doses of $200-3600 \mathrm{mg} /$ day; they also lower the risk of cardiovascular diseases [9]. The hypolipaemic effect is dose-dependent. RYR studies have usually been short-term, lasting from 4 - 12 weeks, and involving small study groups [7], with the exception of the Chinese Coronary Secondary Prevention Study (CCSPS) [10, 11].

The CCSPS was a multicentre study in which 66 hospitals participated and involved 4,870 patients aged $18-75$ years, post-myocardial infarction, with TC 4.40-6.47 $\mathrm{mmol} / \mathrm{L}$, who were given the formulation Xuezhikang (purified RYR extract), $600 \mathrm{mg}$ twice a day, (monacolin 2.5-3.2 mg/capsule) vs. placebo [11]. Taking Xuezhikang for an average of 4 years was associated with a significant reduction of TC by $10 \%$ $(\mathrm{p}<0.001)$, LDL-C by $17.6 \%(\mathrm{p}<0.001)$ and TG by $15.2 \%$ $(\mathrm{p}<0.001)$, and a higher concentration of HDL-C by $4.2 \%$ $(\mathrm{p}<0.001)$. This lipid profile improvement was accompanied by a clinical benefit in the form of reducing the incidence of non-fatal myocardial infarction RR: 0.38 [(95\% Cl: 0.27-0.54); $\mathrm{p}<0.001]$, coronary deaths RR: 0.69 [(95\% Cl: $0.52-0.88)$; $\mathrm{p}=0.005]$, coronary revascularisations RR: 0.64 [(95\% Cl: 0.47-0.86); $\mathrm{p}<0.004]$, cardiovascular deaths RR: 0.70 [(95\% $\mathrm{Cl}: 0.54-0.89) ; \mathrm{p}=0.005]$, and deaths in general RR: 0.67 [(95\% Cl: $0.52-0.82) ; \mathrm{p}=0.0003]$.

From the CCSPS, 1,445 older patients aged 65-75 were isolated, i.e. patients at a higher risk, and the effects of RYR on cardiovascular episodes were assessed [11]. Among the patients taking Xuezhikang $(\mathrm{n}=735)$, as compared to placebo $(\mathrm{n}=710)$, there were $36.9 \%$ less $(\mathrm{p}=0.0001)$ coronary episodes, $31 \%$ less $(\mathrm{p}=0.04)$ coronary deaths, $31.9 \%$ less $(\mathrm{p}=0.01)$ total deaths, and $44 \%$ less $(\mathrm{p}=0.04)$ strokes.

Meta-analyses of clinical studies involving RYR were published, which evaluated its effects on lipid profile [5], cardiovascular episodes [12] and therapy safety [13].

When it comes to the effects on lipid concentration, the meta-analysis by Gerards et al. deserves particular attention due to their comprehensive evaluation, i.e. of the hypolipaemic effects of RYR in 13 placebo controlled studies, in comparative studies vs. statins (3 studies) and vs. a different therapy than statins (4 studies) [5]. Five clinical trials were conducted in Europe and North America, and 14 in China.

A total of 6,663 subjects took part in all the 20 studies, the majority in the CCSPS. With the exception of the longest observational period of 3.5 years in the CCSPS, the observational periods in other studies ranged from $2-$ 24 months. The RYR daily dose ranged 1,200 - 4,800 mg with a monacolin $\mathrm{K}$ content of $4.8-24 \mathrm{mg}$ - mean daily dose $10.8 \mathrm{~g}$ ).

In studies without active control, LDL-C level reduction in patients taking RYR ranged from $0.5-1.59 \mathrm{mmol} / \mathrm{L}$. A pooled difference in LDL-C amounted to $-1.02 \mathrm{mmol} / \mathrm{L}$ (95\% Cl from -1.20 to -0.83 ), TC: $-1.0 \mathrm{mmol} / \mathrm{L}$ (from -1.23 to -0.77 ) and TG: $-0.26 \mathrm{mmol} / \mathrm{L}(-0.35$ to -0.17$)$. The mean HDL level was $0.07 \mathrm{mmol} / \mathrm{L}$ higher: $0.03-0.11$.

In RYR (monacolin $10 \mathrm{mg} / \mathrm{d}$ ) studies controlled with statins (pravastatin $40 \mathrm{mg} / \mathrm{d}$, simvastatin $10 \mathrm{mg} / \mathrm{d}$, lovastatin $20 \mathrm{mg} / \mathrm{d}$ ) there were no significant differences in lipid levels. The mean LDL-C level difference amounted to $0.0395 \% \mathrm{Cl}$ : (from -0.36 to 0.41$)$, while TC $-0.05 \mathrm{mmol} / \mathrm{L}(-0.28-0.18)$. In a single study controlled with gemfibrozil or three studies with herbal formulations, the LDL reduction amounted to $0.52 \mathrm{mmol} / \mathrm{L}$, compared to the control.

The authors of the meta-analysis point out in their conclusions the clinically and statistically significant effect of RYR on LDL-C reduction, i.e. $1.02 \mathrm{mmol} / \mathrm{L}(\sim 40 \mathrm{mg} / \mathrm{dl})$, and argue that: 'RYR could be a safe and effective therapeutic option for the treatment of dyslipidaemia and cardiovascular risk in statin-intolerant patients.' It was emphasised that despite safety not being a priority in most of the studies included in the meta-analysis, the incidence of liver and kidney function disorders ranged $0-5 \%$ in both the RYR and control groups. The incidence of muscular symptoms ranged from $0-28 \%$ in patients taking RYR and $0-36 \%$ in control groups.

Recently, a meta-analysis of seven Chinese double-blind clinical studies (years 2004-2010) with 10.699 patients aged 50-70 years post a myocardial infarction with bordeline hypercholesterolemia was published [12]. It assessed the effects of RYR on the incidence of cardiovascular episodes. The authors took up the subject because there had been no such meta-analysis untill then. For this purpose they carried out review of publications up to May 2019. RYR extract was taken at a dose $1200 \mathrm{mg} /$ day for a period ranging from 6 weeks to 4.5 years. In four studies (10.549 patients), data relating to the incidence of non-fatal myocardial infarction, fatal myocardial infarction, and revascularisation procedures were avaiable, while in three studies (5676 patients) data relating to sudden deaths.

There were significantly fewer non-fatal myocardial infarctions among patients taking RYR extract, compared to placebo (RR: $0.42 ; 95 \% \mathrm{Cl}: 0.34-0.52 ; \mathrm{p}<0.00001$ ). The incidence of fatal myocardial infarction was also lower, although insignificantly (RR: 0.78 ; 95\% Cl: 0.55-1.10; $\mathrm{p}=0.16$ ). The difference in revascularisation procedures was also significant (RR: $0.58 ; 95 \% \mathrm{Cl}: 0.53-0.94 ; \mathrm{p}=0.02$ ), also in sudden deaths (RR: $0.71 ; 95 \% \mathrm{Cl}$ : 0.53-0.94).

In 6 clinical studies from the above-mentioned metaanalysis, the weighted mean of the LDL-C level difference between patients taking RYR and those on placebo amounted to $-20.70 \mathrm{mg} / \mathrm{dl}$ (95\% Cl -24.51 to -16.90$)$. TC: $-26.61 \mathrm{mg} / \mathrm{dl}$ (-35.65 to -21.58$)$, and TG: $-24.69 \mathrm{mg} / \mathrm{dl}(-34.36$ to -15.03$)$, HDL-C: $+2.71 \mathrm{mg} / \mathrm{dl}$ (1.24 to 4.17$)$.

Data relating to therapy safety was given in 4 out of 7 studies included in the meta-analysis (10,549 patients). There were no differences in the incidence of severe adverse events in patients taking RYR at a dose of, $200 \mathrm{mg} /$ day for a period ranging from 6 weeks to 4.5 years, compared to control groups. In the largest CCSPS clinical sample, a nonsignificant increase in the liver and kidney markers was observed in patients taking RYR. In 3 studies - allergic 
reactions, gastrointestinal symptoms and myalgia were observed in RYR groups, while in 2 studies - kidney function disorders.

Recently, a meta-analysis of 53 randomised control studies with the use of RYR as a single formulation and in combination with other nutraceutics, was published, which evaluated the safety of monacolin K [13]. The meta-analysis included 4,437 patients in the RYR group and 4303 in the control group. No increased risk of muscular symptoms or severe adverse reactions was demonstrated in patients taking RYR, compared to the control group [respectively, OR: 0.94; (95\% Cl: 0.50-1.65) and OR: 0.59 [(95\% Cl: 0.50-0.69)].

Nevertheless, it must be noted that RYR contains lovastatin and some products correspond to the dose of $10 \mathrm{mg}$ monacolin K, i.e. $10 \mathrm{mg}$ of lovastatin. Therefore, they might cause the same adverse reactions as in statins. Myopathy, gastrointestinal symptoms, elevated liver enzyme levels, and recently, erectile dysfunction were reported. All these potential risks are pointed out by, among others, Banach et al. [2] as well as Farkouh and Baumgatel [7].

RYR and complex products containing RYR, as well as other nutraceutics, are dietary supplements and, as such, are sold over the counter. There is concern that they might be seen as natural agents that significantly reduce cholesterol levels; however, their hypolipaemic effect is weaker than that of strong statins. They will not replace those drugs, although they might be used in combination with ezetimibe in statinintolerant patients or for primary prevention in people with mild to moderate hypercholesterolemia.

Armolipid Plus. This is a complex nutraceutic containing RYR (200 mg), Monacolin K (3 mg), berberine (500 mg), Policosanol (10 mg), folic acid (0.2 mg), Astaxanthin (0.5 mg) and coenzyme Q10 (2 mg) in a single tablet. Of the complex hypolipaemic nutraceutics, this is the one best known from clinical studies in terms of lipid reduction and safety of use. According to Banach et al.: 'The only recommendation that can be given in terms of complex nutraceutics is Armolipid Plus' [3].

Recently, a group of experts collected evidence from clinical studies for the effectiveness of Armolipid Plus in terms of the reduction of TC and LDL-C levels in patients with mild to moderate hypercholesterolemia. A review of randomised clinical studies was carried out, of which 7 were placebocontrolled studies, 2 were ezetimibe-controlled studies, and 4 were real life studies which compared the effects of adding Armolipid Plus to a diet with a diet alone. A total of 500 patients participating in all 7 studies. Treatment periods ranged from $6-48$ weeks. The mean TC reduction compared to control groups amounted to $1-21 \%$, while LDL-C $15-31 \%$. The review authors stated that 'the primary cause of the differences was probably the severity of dyslipidaemia, as the reductions of these parameters can be proportional to original values.' It also turned out that the results of the real life studies remain congruent with those observed in the randomised clinical studies. Therefore, the review by Bariossa et al. indicates that the effectiveness of Armolipid Plus is similar to that of weaker statins. The observation that in statin-intolerant patients, adding Armolipid Plus to ezetimibe leads to an additional reduction of TC and LDL-C by $10 \%$ is also clinically significant.

The ADHERENCE study deserves particular attention. The study included 100 patients with coronary disease who were subjected to the coronary angioplasty procedure, and did not tolerate large doses of statins, evaluated the effectiveness and tolerability of low-dose statin (LDS) + Armolipid Plus, compared to low-dose statin alone [15]. After 3 months, in patients taking LDS + Armolipid Plus, the LDL-C level was significantly lowered $(\mathrm{p}<0.0001)$, and $70 \%$ of the patients obtained values of $<70 \mathrm{mg} / \mathrm{dl}$, while no patient on LDS alone obtained such values. Three patients from each group were excluded from the study due to myalgia.

Recently, in 100 patients with coronary heart disease who did not tolerate large statin doses, the LDS + ezetimibe therapy and the LDS + Armolipid Plus therapy were compared in terms of obtaining an LDL-C concentration of $<70 \mathrm{mg} / \mathrm{dl}$ [17]. After 3 months, 33 patients treated with LDS + Armolipid Plus achieved the therapy target, which was sustained for 6 months. In patients who did not achieve the target, a triple therapy with LDS + ezetimibe + Armolipid Plus was used. LDL-C $<70 \mathrm{mg} / \mathrm{dl}$ was achieved in 28 out of 36 patients.

There is also a meta-analysis of 14 randomised controlled studies with Armolipid Plus, which included, 159 patients with dyslipidaemia (14 studies) and hyperglycaemia (10 studies) [18]. An improved lipid profile and glucose levels were demonstrated. In patients taking Armolipid Plus, the LDL-C plasma level dropped by $23.85 \mathrm{mg} / \mathrm{dl}(\mathrm{p}<0.001)$, triglycerides were lowered by $13.83 \mathrm{mg} / \mathrm{dl}(\mathrm{p}<0.001)$, while HDL-C increased by $2.53 \mathrm{mg} / \mathrm{dl}(\mathrm{p}<0.001)$, compared to control. Fasting blood sugar level decreased by $2.59 \mathrm{mg} / \mathrm{dl}$ $(\mathrm{p}<0.01)$. The improved lipid profile depended neither on the supplementation duration, nor on the baseline lipid level.

In summary, RYR products and complex nutraceutics that contain it are supplements and - in terms of hypolipaemic effects - will not replace strong statins, which are very well documented when it comes to their effectiveness in reducing cardiovascular episodes, cardiovascular deaths, and all deaths $[18,19]$. Supplements with monacolin K, which is a natural lovastatin, are not entirely devoid of adverse reactions, including the likelihood of statin-associated muscle symptoms (SAMS), of which every physician and every patient should be aware. The problem has not yet been fully explained. There are no studies that would meet the registration requirements to which drugs are subject. Because nutraceutics are not drugs, their use might not be supervised by a doctor and the awareness that they contain statins may be limited. Most clinical data were collected in relation to Armolipid Plus; therefore, in the case of total statin intolerance, attempts can be made to use it in combination with ezetimibe.

RYR: FDA and EFSA opinions. Nutraceutics are understood as dietary products combining nutritional values and features of pharmaceutical agents. The applicable legal system does not officially define them as a product group. The plantderived ingredients discussed in the presented are often ingredients in products marketed as food supplements.

'Food supplements' refers to foodstuffs the purpose of which is to supplement the normal diet in the form of concentrated sources of nutrients, or other substances with a nutritional or physiological effect [20]. They are not medicinal products despite being in the same form as medicinal products capsules, tablets, drops and other similar forms, powder sachets, liquid ampoules, drop dispensing bottles - designed to be taken in measured small unit quantities. A dietary 
supplement, as a food product, must meet legal requirements for food products, while drugs must meet the requirements of the pharmaceutical law.

Sometimes, it is very difficult to differentiate between a dietary supplement and a medicinal product. It might happen that a dietary supplement has the same ingredients as a drug. The substances described in the current article, such as monacolin $\mathrm{K}$, are good examples. Substance doses with proven medicinal effects should be used in drugs only.

Labelling and methods of labelling, as well as presentation and advertisements of dietary supplements, must not imply that these products prevent, treat or cure human diseases [21]. However, when it comes to food products, nutritional and health claims can be used under the terms and conditions laid down in relevant legal regulations [22]. With regard to the applicable law, there are doubts relating to qualifying RYR products with monacolin $\mathrm{K}$ as dietary supplements..

Monacolin K was isolated in 1978 from the fungus Aspergillus terreus and given the name lovastatin. On 1 September 1987, the American Food and Drug Administration (FDA) approved lovastatin as a drug for clinical use under the name Mevacor. Since then, further statins have been introduced into clinical practice, but RYR products with monacolin $\mathrm{K}$ are not approved by the FDA as food, including dietary supplements.

In 2011, the European Food Safety Authority (EFSA) issued an opinion relating to health claims, in which it argued that there is a causative relationship between the intake of monacolin $\mathrm{K}$ from RYR and keeping normal blood LDL cholesterol level [23]. The European Commission approved the following health claim to be used within the European Union: 'Monacolin $\mathrm{K}$ from red yeast rice contributes to the maintenance of normal blood cholesterol concentrations.' The following prerequisites for the use of this claim were stated: 'The claim may be used only for food which provides a daily intake of $10 \mathrm{mg}$ of monacolin $\mathrm{K}$ from red yeast rice' [24]; however, the claim itself does not automatically mean that the substance it relates to will be approved for marketing.

It must be emphasised that RYR formulations may contain impurities, such as the toxic by-products of fermentation nephrotoxic and hepatotoxic citrinin. Taking the above into account, in 2014, the European Commission established the maximum acceptable citrinin level in dietary supplements based on rice fermented with Monascus purpureus, which is 2,000 pg of citrinin/1 kg of a dietary supplement [25].

In 2018, the European Food Safety Authority (EFSA), regarding the safety of monacolin obtained from rice fermented with Monascus purpureus (RYR), stayed the opinion that monacolin $\mathrm{K}$ in the form of lactone is identical to lovastatin - a drug used in the treatment of hypercholesterolemia. EFSA stated that taking monacolin from RYR in the form of dietary supplements may lead to a level of exposure to monacolin $\mathrm{K}$ that is equal to the therapeutic doses of lovastatin [26].

EFSA experts point out the possibility of similar adverse reactions to those occu ring when using lovastatin, and found that the available information on adverse reactions are sufficient by stating that monacolins from RYR used in dietary supplements in doses of $20 \mathrm{mg}$ /day 'cause serious safety concerns'. It was also noted that there were cases of severe adverse reactions from using monacolins from RYR at a dose of only $3 \mathrm{mg} / \mathrm{day}$. The experts concluded that exposure to monacolin $\mathrm{K}$ from RYR may lead to severe adverse reactions related to the liver and to the musculoskeletal system, including rhabdomyolysis.

Berberine. Berberine, an isoquinoline alkaloid, isolated from the Chinese herb Coptis chinensis or Berberis, characterised by a wide spectrum of pharmacological properties [27]. Berberine hydrochloride is a well-known alkaloid, commonly used to treat diarrhoea. Recent studies have indicated that it is also effective in treating malaria, hypertension and tumours, as well as showing neuroprotective and hypolipaemic properties [27, 28]. Berberine has been attributed with antiatherosclerotic effects, which is associated with hypolipaemic, anti-inflammatory, and hypotensive properties, as well as with glucose level reduction and inhibition of the proliferation of vascular smooth muscle cells $[29,30]$.

The hypolipaemic effects of Bberberine are associated with increasing the expression of the LDL receptors, which suggests a mechanism similar to that of statins [31], and with lowering the expression of PCSK9 (Protein Convertase Subtilisin KexinType 9) in the HepG2 cells [32]. Berberine can also lower serum cholesterol concentration by inhibiting lipid synthesis in hepatocytes by activating the AMP-activated protein kinase (AMPK) $[29,33]$. It also shows protective effects on LDL oxidation and ox-LDL induced cytotoxicity on endothelial cells $[29,34]$. Berberine significantly reduces the concentration of triglycerides (TG), which is attributed to the inhibitory effects on the AMP kinase $[35,36]$.

In the first study, which evaluated the effect of administering berberine $500 \mathrm{mg}$ twice a day for three months in Chinese patients with hypercholesterolemia (cholesterol $>5.2 \mathrm{mmol} / \mathrm{L}$ ), a significant reduction $(\mathrm{p}<0.0001)$ of total cholesterol (TC) level by $29 \%$ was observed, LDL-C by $25 \%$ and triglycerides by $35 \%$, compared to the placebo group [37]. Berberine was also assessed in meta-analyses [38, 39, 40]. The berberine dose in those studies ranged from $0.5 \mathrm{~g}-1.5 \mathrm{~g}$ per day, while the study duration ranged from $8-52$ weeks.

Dong et al. in their meta-analysis, analysed 11 randomised controlled studies with 874 subjects [39]. Administering berberine $(n=464)$ caused a significant reduction in total cholesterol level (mean difference - $0.61 \mathrm{mmol} / \mathrm{L}$ ), compared to the control group $(n=410)$. The triglyceride level reduction amounted to $-0.50 \mathrm{mmol} / \mathrm{L}$, while LDL-C to $-0.65 \mathrm{mmol} / \mathrm{L}$. Conversely, HDL-C level increased by $0.05 \mathrm{mmol} / \mathrm{L}$. The authors of the meta-analysis also made a comparison between using berberine + Simvastatin vs. Simvastatin alone. Adding berberine significantly reduced mean total cholesterol concentration $(-0.95 \mathrm{mmol} / \mathrm{L} ; \mathrm{p}=0.02)$, triglycerides $(-0.58$ $\mathrm{mmol} / \mathrm{L} ; \mathrm{p}=0.02)$ and LDL-C $(-0.61 \mathrm{mmol} / \mathrm{L} ; \mathrm{p}=0.02)$, but had no significant impact on HDL-C (-0.07 mmol/L: $\mathrm{p}=0.56)$. Adverse reactions were observed, such as constipation, diarrhoea, flatulence and a bitter taste in the mouth, although these did not lead to a discontinuation of therapy.

A beneficial additional impact of berberine $(500 \mathrm{mg}$ t.i.d administrated for 90 days) when added to bezafibrate therapy (400mg b.i.d) was observed in patients with mixed dyslipidaemia (TC $>5.2 \mathrm{mmol} / \mathrm{L}$, TG $>1.7 \mathrm{mmol} / \mathrm{L}$ ). In this study, berberine with Bezafibrate lowered TG by $2.6 \pm$ $0.8 \mathrm{mmol} / \mathrm{L}$, while bezafibrate alone by $1.3 \pm 0.7 \mathrm{mmol} / \mathrm{L}$ $(\mathrm{p}=0.007)$. The total cholesterol concentration reduction amounted to, respectively, $6.3 \pm 0.7$ vs. $4.6 \pm 1.2 \mathrm{mmol} / \mathrm{L}$ $(\mathrm{p}=0.005) . \mathrm{LDL}-\mathrm{C} 3.4 \pm 0.6$ vs. $2.2 \pm 1.3 \mathrm{mmol} / \mathrm{L}(\mathrm{p}=0.037)$ [41]. 
Mazza et al., on the other hand, showed that in statinintolerant patients with hypercholesterolemia and a moderate to high cardiovascular risk, using ezetimibe with a combination of nutraceutics (Monacolin K, berberine Hydrochloride, t-Resveratrol, Quercetin, Chromium) caused a higher reduction of TC and LDL-C, compared to a treatment with ezetimibe alone [42]. The reduction amounted to, respectively, $-25.9 \%$ vs. $15 \%$ ( $\mathrm{p}<0.05)$, and $-38.7 \%$ vs. $21 \%$ $(p<0.05)$. No significant changes were observed in the case of TG $(-9.4 \%$ vs. $-11.7 \%)$ and HDL-C (+4.2\% vs. $1.1 \%)$. The authors conclude that in statin-intolerant patients, adding the said complex formulation of nutraceutics to ezetimibe improves the impact on TC and LDL-C while remaining safe.

In clinical studies on dyslipidaemic patients, $B$ berberine was also used in combination with other hypolipaemic nutraceutics, such as red rice, policosanol, artichoke, silymarin, chitosan, Morus Alba extract $[1,32]$. Pirro et al. conducted a meta-analysis of 14 studies with 1,670 subjects taking nutraceutics ( $3 \mathrm{mg}$ of monacolin $\mathrm{K}, 10 \mathrm{mg}$ of policosanol, $500 \mathrm{mg}$ of berberine), and 1,484 subjects in the control group [17]. The supplementation reduced total cholesterol (-26.15 mg/dl; p<0.001), LDL-C (-23.85 mg/dl; $\mathrm{p}<0.001)$ and triglycerides $(-13.83 \mathrm{mg} / \mathrm{dl} ; \mathrm{p}<0.001)$, and increased HDL-C level $(2.53 \mathrm{mg} / \mathrm{dl} ; \mathrm{p}<0.001)$. Blood sugar level was also lowered $(-2.59 \mathrm{mg} / \mathrm{dl} ; \mathrm{p}=0.010)$. The above studies show that using berberine alone or in combination with other nutraceutics has a beneficial effect on lipid profile and can be considered as a therapy in patients with hyperlipidaemia. It was also shown that berberine taken alone and in combination with other nutraceutics reduces inflammatory markers, such as CRP, ICAMs, ICAM-1, VCAM-1, IL-C, MCP-1, which can be of importance in preventing atherosclerosis [45]. However, to-date, there have been no studies evaluating the impact of berberine on cardiovascular risk.

Bergamot. Bergamot - bergamot orange (Citrus bergamia), belongs to the citrus fruits and considered a hybrid of bitter orange and lemon, grown mainly in Italian Calabria. Essential oils from bergamot peel are widely used in the perfume, cosmetic, food, and pharmaceutical industries [44]. Bergamot fruit juice, on the other hand, shows health benefits arising from its anti-inflammatory, anti-oxidative and cholesterol reducing properties. Bergamot extracts have a positive impact on the carbohydrate and lipid balance [44, 45].

Bergamot composition differs from that of other citrus fruits, especially in terms of the content of flavonoids, such as: neocriocitrin, naringin, neohesperidin, rutin, neodesmin, rhoifolin, and poncirin [46]. Bioactive components extracted from bergamot peel, such as brutieridin, melitidin, neocriocitrin, and naringin, which demonstrate significant cholesterol reducing effects, and an inhibitory action on the internal and middle carotid artery membrane progression [47]. Other properties attributed to the bergamot flavonoids are ant-ioxidative, anti-inflammatory and anti-atherosclerotic effects $[45,48,49]$.

Three flavonoids extracted from bergamot peel, belonging to the fraction 3-hydroxy-3-methylglutaryl flavone (HMGF, i.e. brutieridin, melitidin, and MMG neocriocitrin), have similar effects to those of statins by inhibiting HMGCoA reductase and ACAT (acetyl-CoA acetyltransferase: cholesterol), which leads to a lower production of cholesterol esters and reducing the cholesterol transport in blood [3].
Flavonoids, such as naringin and neocriocitrin, melitidin and rutin, inhibit the LDL cholesterol oxidation and the adenosine-monophosphate-kinase (AMPK) activation, which suggests preventive antiatherosclerotic effects [45, 47]. Another possible mechanism of action of bergamot is an increased cholesterol elimination with faeces by lowering its absorption in the intestine and increasing the turnover and excretion of bile acids $[3,45]$.

There are not many studies related to the hypolipaemic action of bergamot, although those that are available are promising $[50,51]$. The first studies were conducted on animals, especially mice and rats. Administering $1 \mathrm{ml}$ of bergamot juice per day for 30 days to rats with diet-induced hypercholesterolaemia caused a significant reduction of total cholesterol concentration by $29.3 \%$, triglycerides by $46 \%$, and LDL cholesterol by $51.7 \%$, as well as a $27.6 \%$ increase of HDL cholesterol, compared to the control group [52]. In the studies on rats with diet-induced hypercholesterolaemia, the effects of simvastatin and HMGF on lipids was evaluated [53]. Total cholesterol level was significantly reduced by, respectively, $30 \%$ and $20 \%$, triglycerides by $32 \%$ and $20 \%$, and LDL cholesterol by $24 \%$ and $40 \%$.

Studies were conducted on patients with dyslipidaemia, in which Lamiquiz-Moneo et al. analysed 12 studies (10 interventional and 2 observational), which included 870 adults aged 27-77 [51]. The group consisted of patients with overweight, obesity and other risk factors or metabolic syndrome, as well as patients with mixed hyperlipidaemia and patients with hypercholesterolaemia and ischaemic heart disease. The studies used bergamot in doses ranging from $500 \mathrm{mg} /$ day $-1,500 \mathrm{mg} /$ day, while the intervention duration ranged from 1 month - 6 months. The total cholesterol reduction ranged from $12.3-31.3 \%$, LDL-C from $7.6-40.8 \%$, while TG from 11.5 - 39.5\%.

Mollace et al. recruited 237 patients with mixed hyperlipidaemia, who were administered bergamot fractions (BPF: neocriocitrin, naringin, neohesperidin) at the doses $500 \mathrm{mg}, 1,000 \mathrm{mg}$ and 1,500 $\mathrm{mg}$ per day, as well as placebo for 30 days [44]. The patients were divided into 4 groups: $\mathrm{A}(\mathrm{n}=104)$, patients with hypercholesterolaemia (LDL-C > $130 \mathrm{mg} / \mathrm{dl}$ ); B $(n=42)$, patients with mixed hyperlipidaemia: C $(n=59)$ patients with mixed hyperlipidaemia and hyperglycaemia, and $D(n=32)$, patients with hyperlipidaemia who stopped their simvastatin treatment due to adverse reactions (myalgia, increased serum CK levels). The last group was treated with $\mathrm{BPF}$ only at a dose of $1,500 \mathrm{mg} /$ day for 30 days, 60 days after stopping the statin use. In groups $\mathrm{A}+\mathrm{B}+\mathrm{C}$, the treatment with $500 \mathrm{mg}$ and $1,000 \mathrm{mg}$ of bergamot led to a significant reduction in total cholesterol (TC) by $21.8 \%$ and $29.4 \%$, respectively, compared to placebo $0.1 \%$ ( $\mathrm{p}<0.001)$, reduction of LDL-C by $24.1 \%$ and $30.6 \%$ vs. $1.1 \%$ in the placebo group $(\mathrm{p}<0.001)$, as well as a significant increase of HDL cholesterol by $22.3 \%$ and $40.1 \%$, respectively, vs. $1.2 \%(\mathrm{p}<0.001)$. In patients with higher TG levels, these lipids were reduced by $28.2 \%$ in the group treated with bergamot at $500 \mathrm{mg} /$ day, and $37.9 \%$ in the group taking $1,000 \mathrm{mg} /$ day, compared to the placebo group where the reduction was only $0.1 \%(\mathrm{p}<0.001)$.

In patients with mixed hyperlipidaemia and hyperglycaemia, blood glucose levels were lowered by $18.9 \%$ and $22.4 \%$ in the bergamot groups, compared to $0.5 \%$ $(\mathrm{p}<0.0001)$ in the placebo group. In the group of patients who stopped the statin treatment and took 1,500 mg BPF/ day, the reduction of TC and LDL-C levels amounted to 25\% 
and $27.6 \%$, respectively, compared to placebo. No adverse reactions were observed. The authors of the current study suggest that using bergamot in patients with metabolic disorders can serve as an alternative therapy in the case of statin-intolerance. The beneficial effects on lipids and glycaemia might potentially reduce the cardiovascular risk $[45,46]$, although there is no evidence for that based on clinical studies. Bergamot might also be added to statins, which allows achieving a better therapeutic effect.

In 77 patients with mixed hyperlipidaemia (baseline LDL-C > $160 \mathrm{mg} / \mathrm{dl}, \mathrm{TG}>225 \mathrm{mg} / \mathrm{dl}$ ), Gliozzini et al. used $10 \mathrm{mg}$ (16 persons) or $20 \mathrm{mg}$ (16 persons) Rosuvastatin or bergamot alone at a dose of 1,000 mg BPF per day (phenols: neocriocitrin, naringin and neohesperidin; $n=15$ patients), or bergamot in combination with Rosuvastatin at a dose of $10 \mathrm{mg}$ (15 patients) [54]. Each of the groups were treated for 30 days and compared to placebo. The combined therapy of bergamot plus rosuvastatin (10 $\mathrm{mg}$ per day) reduced LDL-C by $53 \%$, triglycerides by $36 \%$, and increased HDL cholesterol by $37 \%$. Compared to placebo, LDL-C levels were comparable to the effect achieved after the treatment with Rosuvastatin alone at a dose of $20 \mathrm{mg}(90 \mathrm{mg} / \mathrm{dl}$ vs. $87 \mathrm{mg} / \mathrm{dl})$, while in terms of triglycerides, the result was better $(202 \mathrm{mg} / \mathrm{dl}$ vs. $152 \mathrm{mg} / \mathrm{dl})$, the same as with HDL-C (52 mg/dl vs $48 \mathrm{mg} / \mathrm{dl})$ [54]. The lipid concentration changes were accompanied by a reduction in Malondialdehyde, Ox-LDL receptor 1 (LOX1), and phosphor-PKB, which are biomarkers of oxidative vessel damage.

Summing up the results of bergamot studies conducted todaste, it can be concluded that bergamot shows effectiveness and safety in patients with dyslipidaemia and other cardiovascular risk factors. Therefore, it can potentially lower the cardiovascular risk, although this has yet to be proved in clinical studies.

Medical indications for the use of nutraceutics. For statin-intolerant patients, the International Lipid Expert Panel recommends red yeast rice, Armolipid and berberine from among all the nutraceutics [4]. At the core of treating lipid disorders is whether the therapy lowers the risk of cardiovascular episodes. Based on Chinese studies, the only nutraceutic that has met this condition is red yeast rice. The content of monacolin K (lovastatin) varies in particular RYR formulations, which does not always correspond to the manufacturers' declarations.

Armolipid Plus, a complex nutraceutic, contains at least2o ingredients with documented hypolipaemic activities RYR (3 g of monacolin) and berberine, while RYR also reduces the risk of cardiovascular episodes. Both RYR and berberine in Armolipid are present in a specific amount per daily supplement dose. However, Armolipid Plus, as well as other RYR products, are to be taken with the consent of the doctor. Monacolin $\mathrm{K}$ is a statin and can interact with other drugs. Although the likelihood of muscular symptoms is low, it cannot be completely ruled out. One must be aware that nutraceutics with RYR and berberine will never replace modern pharmacotherapy, which can reduce $\mathrm{LDL}-\mathrm{C}$ concentrations to the very low levels required for secondary prevention. Therefore, supplements can only serve as an alternative in the case of statin intolerance, usually in combination with ezetimibe, and possibly for primary prevention in persons with mild to moderate hypercholesterolemia.
According to the European Society of Cardiology (ESC) and the European Atherosclerosis Society (EAS), purified red yeast rice formulations 'can be considered for patients with elevated cholesterol levels who do not qualify for statin treatment in the light of cardiovascular risk' [1]. However, when it comes to berberine, experts argue that, due to the lack of highly specialised randomised clinical studies, there is a need for further studies relating to the effectiveness of the said supplement in terms of reducing LDL cholesterol concentration. Bergamot, on the other hand, was not listed as one of the formulations that could be considered for dyslipidaemia treatment.

\section{CONCLUSIONS}

Among the nutraceutics with cholesterol lowering properties, RYR and Armolipid Plus are the leading formulations, based on clinical studies which have shown that the cholesterol reducing properties of those formulations correspond to a lower risk of cardiovascular diseases. They can be combined with ezetimibe as an alternative to statins if a patient is statin-intolerant, and can be used in persons with moderate hypercholesterolaemia. There is no clear-cut position on bergamot and berberine due to the lack of larger and longer studies.

Table 1. Nutraceutics in statin-intolerant patients (International Lipid Export Panel in own modification)

\begin{tabular}{|c|c|c|c|c|c|}
\hline Product & Daily doses & $\begin{array}{l}\mathrm{LDL}-\mathrm{C} \\
\text { reduction }\end{array}$ & $\begin{array}{l}\text { Adverse } \\
\text { reactions }\end{array}$ & Class* & Level ${ }^{* *}$ \\
\hline Red rice & $\begin{array}{l}1,200-4,800 \text { mg (3- } \\
10 \text { mg monacolin } \mathrm{K})\end{array}$ & $\begin{array}{c}-15 \% \text { to } \\
-25 \%\end{array}$ & $\begin{array}{l}\text { Monacolin } \\
\text { dose- } \\
\text { dependent } \\
\text { symptoms, } \\
\text { typical for } \\
\text { statins }\end{array}$ & 1 & A \\
\hline Bergamot & $500-1500 \mathrm{mg}$ & $\begin{array}{c}-15 \% \text { to } \\
-25 \%\end{array}$ & None observed & $\mathrm{llb}$ & B \\
\hline Berberine & $500-1500 \mathrm{mg}$ & $\begin{array}{c}-15 \% \\
\text { to- } 25 \%\end{array}$ & $\begin{array}{c}\text { Mainly } \\
\text { gastrointestinal }\end{array}$ & 1 & A \\
\hline $\begin{array}{l}\text { Armolipid } \\
\text { Plus }\end{array}$ & $\begin{array}{c}200 \mathrm{mg} \text { of red rice } \\
\text { (monacolin extract } \\
3 \mathrm{mg} \text {, Policosanol } \\
10 \mathrm{mg} \text {, berberine } \\
500 \mathrm{mg} \text {, folic acid } \\
0.2 \mathrm{mg} \text {, Astaxanthin } \\
0.5 \mathrm{mg} \text {, and coenzyme } \\
\text { Q } 2 \mathrm{mg} \text { ) }\end{array}$ & $\begin{array}{c}-15 \% \text { to } \\
-30 \%\end{array}$ & None observed & 1 & $A$ \\
\hline
\end{tabular}

*class of recommendations; **level of evidence

\section{REFERENCES}

1. Mach F, Baigent C, Catapano AL, et al. 2019 ESC/EAS guidelines for the management of dyslipidaemias: lipid modification to reduce cardiovascular risk: The Task Force for the management of dyslipidaemias of the European Society of Cardiology (ESC) and the European Atherosclerosis Society (EAS). Eur Heart J. 2019; 41: 111-188. https:// doi: 10.1093/eurheartj/ehz455

2. Banach M, Patti AM, Giglio RV, et al. The role of nutraceuticals in statin intolerant patients. J Am Coll Cardiol. 2018 Jul 3; 72(1): 96-118. https:// doi: 10.1016/j.jacc.2018.04.040

3. Banach M, Bruckert E, Descamps OS, et al. The role of red yeast rice (RYR) supplementations in plasma cholesterol control: a review on expert opinion. Atheroscler Suppl. 2019 Dec; 39: e1-e8. doi: 10.1016/j. atherosclerosissup.2019.08.023 
4. Cicero AFG, Colletti A, Bajrakti G, et al. Lipid lowering nutraceuticals in clinical practice: position paper from International Lipid Expert Panel (ILEP).Arch Med Sci. 2017 Aug; 13(5): 965-1005. https://doi: 10.5114/aoms.2017.69326

5. Gerards MC, Terlou RJ, Yu H, et al. Traditional Chinese lipid-lowering agent red yeast rice results in significant LDL reduction but safety is uncertain: a systematic review and meta-analysis. Atherosclerosis. 2015 Jun; 240(2): 415-23. https:// doi: 10.1016/j.atherosclerosis.2015.04.004

6. Chen $\mathrm{CH}$, Uang YS, Wong ST, et al. Interaction between red yeast rice and CYP450/P-glicoprotein and its implications for the clinical pharmaco-kinetics of lovastatin. Evid Based Complement Alternat Med. 2012; 2012: 127043. https://doi: 10.1155/2012/127043

7. Farkouh A, Baumgärtel C. Mini-review: medication safety of red yeast rice. Int J Gen Med. 2019; 12: 167-171. doi: 10.2147/IJGM.S202446

8. Brouwers JR, Roeters van Lennep JE, Maais AH. Red yeast rice as a cholesterol lowering substance? Caution is warranted. Ned Tijdschr Geneeskd. 2016; 160: D99.

9. Sahebkar A, Serban MC. Gluba-Brzoska A, et al. Lipid-modifing effects of nutraceuticals: an evidence based - approach. Nutrition. 2016; 32: 1179-1192. https://doi: 10.1016/j.nut.2016.04.007

10. Lu Z, Kou W, Du B, et al. Chinese Coronary Secondary Prevention Study. Effect of Xuezhikang, extract from red yeast Chinese rice on coronary events in Chinese population with previous myocardial infarction. Am J Cardiol. 2008; 101: 1689-1693. https://doi.org/10.1016/j. amjcard.2008.02.056

11. Ye P, Lu Zong-Liang, Du Bao-min, et al. Effect of xuezhikang on cardiovascular events and mortality in elderly patients with history of myocardial infarction. A subgroup analysis of elderly subjects from China Coronary Secondary Prevention Study. J Am Geriatr Sci. 2007; 55: 1015-1022. https://doi: 10.1111/j.1532-5415.2007.01230

12. Sungthong B, Yoothaekool C, Promphamorn S, et al. Efficacy of red yeast rice extract in myocardial infarction patients with bordeline hypercholesterolemia: a meta-analysis of randomized controlled trials. Sci Rep. 2020; 10: 2769. https://doi: 10.1038/541598-020-59796-6

13. Fogacci F, Banach M, Mikhailidis DP, et al. Lipid. Blood pressure Metaanalysis Collaboration International Lipid Expert Panel. Safety of red yeast rice supplementation: a systematic review and meta-analysis of randomized controlled trials. Pharmacol Res. 2019; 143: 1-16. https:// doi: 10.1016/j.phrs.2019.02.028

14. Barrios V, Escobar C, Cicero AFG, et al. A nutraceutical approach (Armolipid Plus) to reduce total and LDL cholesterol in individuals with mild to moderate dyslipidemia: a review of clinical evidence. Atheroscler Suppl. 2017; 24: 1-15.https://doi: 10.1016/j.atherosclerosissup.2016.10.003

15. Marazzi G, Campolongo G, Pelliccia F, et al. Comparison of low-dose statin versus low dose statin + Armolipid Plus in high intensity statin intolerant patients with a previous coronary event and percutaneous coronary intervention (ADHERENCE trial). Am J Cardiol. 2017; 120 : 893-897. https://doi: 10.1016/j.amjcard.2017.06.015

16. Marazzi G, Campolongo G, Pelliccia F, et al. Usefulness of low dose statin plus ezetymibe and/or nutraceuticals in patients with coronary artery disease intolerant to high dose statin treatment. Am J Cardiol. 2019; 123: 233-238. https://doi: 10.1016/j.amjcard.2018.09.041

17. Pirro M, Mannarino MR, Bianconi V, et al. The effects of nutraceutical combination on plasma lipids and glucose: a systematic review and meta-analysis of randomized controlled trials. Pharmacol Res. 2016; 110: 76-88, https://doi: 10.1016/j.phrs.2016.04.021

18. Fulcher J, O'Connell R, Voysey M, et al. Efficacy and safety of LDL lowering therapy in men and women: a meta-analysis of individual data from 174000 participants in 26 randomised trials. Lancet. 2019; 385: 1397-1405. https://oi:10.1016/S0140-6736(14)61368-4

19. Cholesterol Treatment Trialists' Collaboration. Efficacy and safety of statin therapy in older people: a meta-analysis of individual participant data from 28 randomised controlled trials. Lancet. 2019; 393: 407-415. https://doi.org/10.1016/S0140-6736(18)31942-1

20. Ustawa z dnia 25 sierpnia 2006 r. o bezpieczeństwie żywności i żywienia Dz. U. z 2006 r. Nr 171, poz. 1225 ze zmianami.

21. Rozporządzenie Parlamentu Europejskiego i Rady (UE) NR 1169/2011 z dnia 25 października 2011 r. w sprawie przekazywania konsumentom informacji na temat żywności, zmiany rozporządzeń Parlamentu Europejskiego i Rady (WE) nr 1924/2006 i (WE) nr 1925/2006 oraz uchylenia dyrektywy Komisji 87/250/EWG, dyrektywy Rady 90/496/ EWG, dyrektywy Komisji 1999/10/WE.

22. Rozporządzenie (WE) nr 1924/2006 Parlamentu Europejskiego i Rady z dnia 20 grudnia 2006 r. w sprawie oświadczeń żywieniowych i zdrowotnych dotyczących żywności.

23. Scientific Opinion on the substantiation of health claims related to monacolin $\mathrm{K}$ from red yeastrice and maintenance of normal blood
LDL-cholesterol concentrations (ID 1648, 1700) pursuant to Article 13(1) of Regulation (EC) No 1924/2006, EFSA Journal 2011; 9(7): 2304.

24. Rozporządzenie Komisji (UE) nr 432/2012 z dnia 16 maja 2012 r. ustanawiające wykaz dopuszczonych oświadczeń zdrowotnych dotyczących żywności, innych niż oświadczenia odnoszące się do zmniejszenia ryzyka choroby oraz rozwoju i zdrowia dzieci, z późniejszymi zmianami.

25. Rozporządzenie Komisji (UE) nr 212/2014 z dnia 6 marca 2014 r. zmieniającego rozporządzenie (WE) nr 1881/2006 w odniesieniu do najwyższych dopuszczalnych poziomów zanieczyszczenia „cytrynina” w suplementach diety na bazie ryżu poddanego fermentacji grzybami Monascus purpureus.

26. Scientific opinion on the safety of monacolins in red yeast rice. EFSA Journal 2018; 16(8): 5368.

27. Song D, Hao J, Fan D. Biological properties and clinical application of berberine. Front Med. 2020, https:// doi: 10.1007/s11684-019-0724-6

28. Cheng Z, Liu S, Wu X, et al. Autologous erythrocytes delivery of berberine hydrochloride with long-acting effect for the hypolipidemia treatment. Drug Deliv. 2020; 27: 283-291. https:// doi: $10.1080 / 10717544.2020 .1716880$

29. Wu M, Wang J, Liu L-T. Advance of studies on anti-atherosclerosis mechanism of berberie. Chin J Integr Med. 2010; 16(2): 188-192.

30. Xie X, Ma X, Zegn S, et al. Mechanisms of berberine for the treatment of atherosclerosis based on network pharmacology. Evid Based Complement Alter Med. 2020, Article ID 3568756, https://doi. org/10.1155/2020/3568756

31. Wei J, Jiang JD, Wu JD, et al. Research on the effective improvement of hyperlipidemia by berberine. Chin J Diabetes (Chin), 2005; 13: 49-51.

32. Adorni MP, Zimetti F, Lupo MG, et al. Naturally occurring PCSK9 inhibitors. Nutrients. 2020 May 16; 12(5): https://doi: 10.3390/ nu12051440

33. Brusq JM, Amcellin M, Grondin P, et al. Inhibition of lipid synthesis through activation of AMP kinase: an additional mechanism for the hypolipidemic effects of berberine. J Lipid Res. 2006; 47: 1281-1288. doi: 10.1194/jlr.M600020-JLR200

34. Hsieh YS, Kuo WH, Lin TW, et al. Protective effects of berberine against low-density lipoprotein (LDL) oxidation and oxidized LDLinduced cytotoxicity on endothelial cells. J Agric Food Chem. 2007; 55: 10435-10437. https://doi: 10.1021/jf071868c

35. Pirillo A, Catapano AL. Berberine, a plant alkaloid with lipid and glucose-lowering properties: from in vitro evidence to clinical studies. Atherosclerosis. 2015; 243(2): 449-61. https://doi: 10.1016/j. atherosclerosis.2015.09.032

36. Poli A, Visioli F. Pharmacology of nutraceuticals with lipid lowering properties: High Blood Press Cardiovasc Prev. 2019; 26: 113-118. https:// doi: 10.1007/s40292-019-00311-x

37. Kong W, Wei J, Abidi P, et al. Berberine is a novel cholesterol-lowering drug working through a unique mechanism distinct from statins. Nat Med. 2004; 10: 1344-1351. https://doi: 10.1038/nm1135

38. Dong H, Wang N, Zhao L, Lu F. Berberine in the treatement of type 2 diabetes mellitus: A Systemic review and meta-analysis. Evid Base Complement Altern Med. 2012: 1-12. https:/doi: 10.1155/2012/591654

39. Dong H, Zhao Y, Zhao L, Lu F. The effects of berberine on blood lipids: A systemic review and meta-analysis on randomized controlled trials. Planta Med. 2013; 79: 437-446, https://doi: 10.1055/s-0032-1328321

40. Lan J, Zhao Y, Dong F, et al. Meta-analysis of the effects and safety of berberine in the treatment of type 2 diabetes mellitus, hyperlipemia and hypertension. J Ethnopharmacol. 2015; 161: 69-81, https://doi: 10.1016/jep2014.09.049

41. Leon-Martinez JM, Martinez-Abundis E, Gonzalez-Ortiz M, et al. Effect of berberine plus bezafibrate administration on the lipid profile of patients with mixed dyslipidemia. A pilot clinical trial. J Med Food. 2020 May 12, https://doi: 10.1089/jmf2020.0029

42. Mazza A, Nicoletti M, Lenti S, et al. Effectiveness and safety of novel nutraceutical formulation addend to ezetimibe in statin-intolerant hypercholesterolemic subjects with moderate-to-high cardiovascular risk. J Med Food. 2020 May 22, https://doi: 10.1089/jmf.2020.0019

43. Meng S, Wang LS, Huang ZQ, et al. Berberine ameliorates inflammation in patients with acute coronary syndrome following percutaneous coronary intervention. Clin Exp Pharmacol Physiol. 2012; 39: 406-11. https://doi: 10.1111/j.1440-1681.2012.05670.x

44. Mollace V, Sacco I, Janda E, et al. Hypolipaemic and hypoglycaemic activity of bergamot polyphenois: From animal models to human studies. Fitoterapia. 2011; 82: 309-316. https://doi: 10.1016/j.fitote.2010.10.014

45. Mannucci C, Navarra M, Calapai F, et al. Clinical pharmacology of citrus bergamia: A systematic review. Phytother Res. 2017; 31: 27-39. https://doi: 10.1002/ptr.5734 
46. Giglio RV, Patti AM, Nikolic D, et al. The effect of bergamot on dyslipidemia. Phytomedicine. 2016;23: 1175-1181. https://doi: 10.1016/j. phymed.2015.12.005

47. Toth PP, Patti AM, Nikolic D, et al. Bergamot reduces plasma lipids, atherogenic small dense LDL and subclinical atherosclerosis in subjects with moderate hypercholesterolemia: A 6 months prospective study. Frontiers Pharmacol. 2016; 6: 299. https://doi: 10.3389/fphar.2015.00299

48. Ferlazzo N, Visalli G, Smerigio A, et al. Flavonoid fraction of orange and bergamot juices protect human lung epithelial cells from hydrogen peroxide-induced oxidative stress. Evid Based Complement Alternat Med. 2015; 957031. https://doi: 10.1155/2015/957031

49. Impelizzeri D, Bruschetta G, Di Paola R, et al. The antinflammatory and antioxidant effects of bergamot ice extract (juBJe) in an experimental model of inflammatory bowel disease. Clin Nutr. 2015; 34: 1146-1154. https://doi: 10.1016/j.clnu.2014.11.012

50. Nauman MC, Johnson JJ. Clinical applicaton of bergamot (Citrus bergamia) for reducing high cholesterol and cardiovascular disease marker. Integr Food Nutr Metab. 2019 Mar 6(2). https://doi: 10.15761/ FNM.10000249

51. Lamiquiz-Moneo I, Gine-Gonzalez J, Alisente S, et al. Effect of bergamot on lipid profile in humans: A systematic review. Crit Rev Food Sci Nutr. 2019 Oct 31: 1-11, https://doi: 10.1080/10408398.2019.1677554

52. Miceli N, Mondello MR, Monforte MT, et al. Hypolipidemic effect of Citrus BergamiRisso et Poileau juice in rats fed a hypercholesterolemic diet. J Agric Food Chem. 2007; 55: 10671-10677. https://doi: 10.1021/ jf071772i

53. Di Donna L, Iacopetta D, Cappello AR, et al. Hypocholesterolaemic activity of 3-hydroxy-3-methyl-glutaryl flavanones enriched fraction from bergamot fruit (Citrus bergamia): "In vivo" studies. J Funct Food. 2014; 7: 558-568. https://doi.org/10.1016/j.jff.2013.12.029

54. Gliozzi MR, Walker S, Muscoli C, et al. Bergamot polyphenolic fraction enhances rosuwastatin-induced effect on LDL cholesterol, LOX-1expression and protein kinase B phophorylationin patients with hyperlipidemia. Intern J Cardiol. 2013; 170(2): 15. https://doi:10.1016/j. ijcard201308.125 